\title{
22 INTELLIGENT CONTRACTING: SOFTWARE AGENTS, CORPORATE BODIES AND VIRTUAL ORGANIZATIONS
}

\author{
Francisco Andrade', Paulo Novais ${ }^{2}$, José Machado ${ }^{2}$ and José Neves ${ }^{2}$ \\ 'Escola de Direito, Universidade do Minho, Braga, PORTUGAL \\ ${ }^{2}$ DI-CCTC, Universidade do Minho, Braga, PORTUGAL \\ fandrade@direito.uminho.pt. \{ pjon,jmac,jneves\}@di.uminho.pt
}

\begin{abstract}
Legal doctrine starts to speak of Inter-systemic electronic contracting, where an important role is plaved by soft bots, i.e., intelligent software agents, which may be fiction as tools controlled by humans or faced as subjects of electronic commerce, or even seen as legal objects or as legal subjects. The use of software agents in electronic commerce scenarios must be connected with the existence of corporate bodies and Virtual Organizations. The issue to be discussed here is whether there should be Commercial Corporations for the use of Software Agents (as mere tools of the companies) or if the agents themselves can be seen as full and active participants in new types of commercial corporations and Virtual Organizations.
\end{abstract}

\section{INTRODUCTION}

In general it may be stated that legal doctrine has established a way of classifying electronic contracts, according to the specific technical way of accomplishing each type of electronic conveying and contracting (Barbagalo, 2001), distinguishing the possibilities of the parties involved to interact through computer devices, where computers are seen as mere communication means, interacting with computer devices and electronic systems, or even considering the case of contracting without human parties interacting at all, leaving all the work to informatics and electronic systems which, in an automatic, and sometimes even autonomous way (according to software developed and put in use on behalf of the contracting parties), produce a sort of "machine only interaction".

Under this distinction, we may speak of different ways of electronically contracting, according to the singularities of human intervention in the contracting process. And it must be faced with the quite interesting, although eventually legally problematic, possibility of inter-systemic electronic contracting.

Inter-systemic contracting can be distinguished from other means of contracting by the degree of human involvement in the process of contract construction. In every conventional means of contracting, through conventional letters, fax, telex (and even in not so conventional ones, as electronic mail), the human intervention always appears at the beginning of any deal (Almeida, 2000; Gentili, 2000; Thoumyre, 1999). However, in inter-systemic contractual relations the whole process of communication and contracting is "between applications" or "between agents" without any human intervention (Elias and Gerard, 1991). The party's computational systems are not only interconnected but are also able to relate among themselves without human intervention. The human beings limit their involvement to organize the computational systems in terms of their necessities of communication and action (Brabagalo, 2001). Henceforth, the machines will act on their own, concluding

Andrade, F., Novais, P., Machado, J., Neves, J., 2007, in IFIP Intcrnational Federation for Information Processing, Volume 243, Establishing the Foundation of Collaborative Networks: cds. Camarinha-Matos, L., Afsarmanesh, H., Novais, P., Analide, C.; (Boston: Springer), pp. 217224. 
contracts on behalf of the parties involved, either in terms of "automatic inter-systemic electronic contracting", which is classical case of contracting through EDI-Electronic Data Interchange, and "intelligent inter-systemic electronic contracting", where one has soft bots capable of acting, learning, modifying instructions and taking decisions (Allen and Widdison, 1996).

The paper is organized as follows. The following section presents the concepts of agent and organization. Afterwards, it is mentioned the use of agents in e-commerce scenarios and intelligent contracting. We will finish giving an opinion formed after considering the relevant factors or evidence about the proposed model, and point out some directions for future work.

\section{AGENTS AND ORGANISATIONS}

Agents are computational entities with a rich knowledge component, having sophisticated properties such as planning ability, reactivity, learning, cooperation, communication and the possibility of argumentation (Figure 1) (Novais, 2003). The use of the agent figure is particularly adequate to such problems. The objective is to build logical and computational models, as well as implementing them, having in consideration The Law Norms and Principles (i.e., legislation, doctrine and jurisprudence). Agent societies may mirror a great variety of structured communities of people, such as commercial societies, with an emphasis to the behavioral patterns, or even the more complex ones, with pre-defined roles of engagement, obligations, contractual and specific communication rules.

Today

Mediators

\section{The Future?}

\section{Initiators}

Figure 1: Agent role

Corporate persons (i.e., an association of individuals which pursue a particular objective), may be understood as real "legal artificial persons", a reason why Emily Weitzenboeck (2001) remarks that "many artificial legal persons are already regarded as person...". Indeed, corporate bodies do not actually have a will of their own ("...legal subjects as collective persons, which really do not hold neither physical characteristics nor will"), being their will formed by the will of the humans (Kemradj, 2002).

Speaking of corporate persons and software agents, we must refer the possibility of the later playing a social role, not only in corporate bodies, but also in the so called Virtual Enterprises (VE), although VEs be understood as "a temporary alliance between globally distributed independent companies working together to improve their competitiveness by sharing resources, skills, risks and costs" (Crispim and Sousa, 2005). 


\section{INTELLIGENT ELECTRONIC CONTRACTING}

One of the possible solutions for considering the issue of consent in electronic intelligent inter systemic contracting, would be treating the whole declarative process as performed by an human. It would be like establishing a legal presumption (Allen and Widdison (1996) call it a "legal fiction"), where all the transactions entered into the computer would be treated as transactions entered by the human trader, thus putting the intention and the whole risk of the transactions "on the person best able to control them, i.e. those who program and control the computer".

The acceptance of this theory would have an obvious impact - the risk of transactions would be entirely put "on the persons who program, control or otherwise use an electronic agent" (Weitzenboeck, 2001), and these would eventually be assigned a sort of liability regime similar to the one related to the use of cars or machines by their owners. "A party may be liable for a damage caused by an object" (Lerouge, 2000). It is a well known principle of Civil Law's liability regime that "a person to whose sphere machines can be assigned to, is supposed to be liable for them. Thus, one shall bear the risk that has the right and ability to control the machine and to receive a (financial) benefit from its use" (Haentjens, 2002). And even if the damages to be caused by agents would most surely not be of a physical order (at least, while it is not considered the existence of robots), but financial and moral (reputation), the truth is that the financial loss and moral (reputation) consequences could become quite burdening. Having this in mind, may we make such an assertion of intention and liability when we are not speaking of machines that one can control, but of most sophisticated engines whose behavior cannot be totally predicted? Would it not be a terrible burden to put on programmers and users - who surely could not be "in such a condition to anticipate the contractual behavior of the agent in all possible circumstances", and so could not be in position of "wanting" each and every "contract which the agent will conclude"? (Sartor, 2002)

Another possibility is related to some sort of "personification" or the granting of legal personality to software agents (Wettig and Zehendner, 2004). But it must be held clear that "personality" is not a "physical" or "natural" concept (Andrade, 1974), it is rather the capability of being a subject of rights and obligations - being important to establish "whether or not the entity can and should be made the subject of a set of legal rights and duties" (Barfield, 2005), its capability of being a centre of production of legal effects (e.g., constitution, modification, and extinction of legal relations).

The issue of social roles looks determinant for the attribution of legal personality, maybe even more determinant than intelligence or self-consciousness. Human beings will (may) play - regardless of the ability to think and learn of each person a social role. Legal persons, although instrumental to man interests, also play social roles. Intelligent software agents may as well, in a near future, engage on a relevant social role and take active part in many activities reserved, until now, to humans. It must be questioned which actors intervene in nowadays human societies. Indeed, it seems obvious that intelligent agents are the newest actors in the global society of the 21 st century, with an impending capability of intervention in the commercial and legal arenas, and even in producing legal effects.

"As explained by Teubner, the leading theorist on the application of autopoiesis to law, an autopoietic social system is "a system of actions / communications that 
reproduces itself by constantly producing from the network of its elements new communications/actions as elements". As Allen and Widdison (1996) refer, and according to Teubner, "legal persons are entities that are constructed within the legal system as "semantic artefact(s)" to which legally meaningful communications are attributed. In other words, entities are described as legal persons when the legal system attributes legally meaningful communications to them. To put it simply, within the legal system, legal persons are those entities that produce legal acts." Obviously, according to this theory, both natural persons as corporate persons, and even intelligent soft bots, might be considered as legal persons. On the contrary, the so called intelligent animals, although deserving legal protection, have not the referred capacity of producing or generating legal acts.

It is important to remember here the distinction between legal subjects and legal objects. As Wettig and Zehendner (2003) put it, "Legal subjects, usually humans, can be holder of rights and obligations. For legal objects (e.g., things, intellectual property rights) this is not possible. These can only be object of legal owner rights". The issue is whether or not software agents may be seen as mere objects, or if they should be considered as real "subjects". According to their characteristics, they look much like real "subjects".

But can software agents be recognized as legal persons? Many difficulties would certainly arise if we intended that purpose (Andrade et al, 2004). But the most crucial issue will always be the one related to liability for acts practiced by software agents (Wettig and Zehendner, 2004), since these are logical entities (whether or not physical entities) capable of multiple and autonomous intervention in the legal arena, whose personification under the law might be seen as a technical way of responding to a social need - the need for more efficient and reliable ways of undertaking actions that the man alone cannot perform or cannot complete in a sufficiently and economically not long time.

The attribution of legal personality to intelligent software agents would have at least two clear advantages (Andrade et al, 2007). To begin with, by the recognition of an autonomous consent (which is not a fiction at all), it would solve the question of consent and of validity of the declarations and contracts enacted or concluded by electronic agents without affecting more than is desirable the legal theories about consent and declaration, contractual freedom, and conclusion of contracts. Secondly, and also quite important, it would "reassure the owners-users of agents" once, by considering the eventual "agents" liability, it could at least limit their own (human) responsibility in terms of the "agents" behaviour (Sartor, 2003). This solution might look rather convenient in all aspects. But, nevertheless, its adoption will not be without difficulties. A relevant issue concerning the legal personhood of electronic agents is that of its "patrimonial duties". In order to exist, a legal person must have, or at least be capable of having, a patrimony. But does it make any sense to attribute a patrimony to an electronic device? Can we imagine a situation of these electronic devices having "patrimonial rights and also be subject to liability for negligent acts or omissions, just as natural persons would" (Weitzenboeck, 2001)? Is it possible for us to state that an electronic device acted in good faith, in bad faith, with knowledge or ignorance of certain circumstances? And how can electronic agents be sued in Court? How? And will contracts enacted by them be enforceable? (Barfield, 2005) Will specific alternative on-line dispute resolution methods be required for e-commerce acted by software agents? These are undoubtedly major difficulties in the attempt of "personification" of such software agents. 
One interesting suggestion of Sartor (2002) in order to overcome some difficulties and to allow the use of software agents in electronic commerce, leads to the creation of companies intended for on-line trading through software agents.

"An easier and less risky way for the agent to make contracts... and to limit the liability of the user (at least, to some extent) is available. This consists in creating companies for on-line trading, which would use agents in doing their business. Such agents would act in the name of a company, their will would count as the will of the company, their legally relevant location would be the company's domicile, and creditors could sue the company for obligations contracted by those agents. The counterparties of an agent could then be warranted by the capital of the company and by the legal remedies available towards defaulting commercial companies" (Sartor, 2002). But under this point of view, software agents are still seen as mere objects, belonging to corporate bodies instead of natural persons. In this view, the software agent is seen as a mere object the corporate body uses. And the consent given by the software agent (a consent that no one will be able to anticipate or control) will be the consent of the corporate body. In this sense, the will of the corporate body will still be formed by the will of its (human) members? Or will it be just the totally aleatory will determined by the action of a software program?

Another interesting possibility is pointed out by Allen and Widdison (1996), making a parallel once again with corporate bodies and speaking of the existence of a hybrid social person, "consisting of a computer and natural person operating in tandem. This "partnership" could exhibit behaviour which is not entirely attributable to either constituent, and yet is the product of their joint efforts. Here we might see something similar to the original idea of the collective of individuals as a single entity possessing social personality (and ultimately legal personality), but the collective would consist of a computer and a natural person".

This suggestion of considering the possibility of a hybrid person, a sort of natural persons and computers (actually software agents), capable of acting a will resulting from the joint efforts of men and software, points out to a new personality composed of man and machine, resulting in an interaction between natural biological (human) intelligence and artificial intelligence, forming thus a different kind of entity with a own will, different from merely human will.

There are interesting views on the constitution of collective entities, integrated not only by humans, but also by corporations and (why not?) by intelligent software (Pacheco, 2001), all this upon the idea that a corporate body never acts directly; it just acts upon the acting of the agents holding a role in its structure. And if human element plays a role in the corporate body, there is apparently no reason why software agents shouldn't also play an important role in a corporation. The question here is to know whether or not we may have not only the above referred hybrid society (constituted by human and by software) but also corporations constituted only by software agents. (Or, in the hypothesis of Sartor (2002), corporations constituted for the use of software agents). These are different possibilities that must be foreseen.

Actually, corporate persons ("an association of individuals which pursues a particular object that is distinct from the human beings which constitute it in such a manner that society starts distinguishing the whole from the individual parts") may be understood as real "legal artificial persons", and that is why Weitzenboeck (2001) notes that "many artificial legal persons are already regarded as persons...". Indeed, Corporate bodies do not actually have a will of their own ("...legal subjects 
collective persons, which really don't possess neither physical characteristics nor will") (Kemradj, 2002), being their will formed by the will of humans.

The truth is that is must be understood that corporate persons are non natural legal persons (and it is quite accurate that common law doctrine distinguishes natural persons and legal persons or corporations), but also that corporate persons are in fact organizations which may be viewed as "a set of interacting agents (human agents or not)" (Pacheco and Carmo, 2003). It may be assumed (at least the possibility of) that not only natural "persons can act for an organization; there is no reason why software agents ....cannot play some roles". Of course, the participation of software agents under current law is not yet possible, because software agents are not legal persons. On the other hand, participation of software agents in corporations would require not only the attribution of a "patrimony" to the agent, but also the rethinking of the rules of functioning and liabilities of the hybrid corporate person. Probably, a new type of corporation should have to be considered.

Speaking of corporate persons and software agents, we must refer the possibility of the later playing a social role not only in corporate bodies, but also in the so called Virtual Enterprises (VE). Although VEs are understood as "a temporary alliance between globally distributed independent companies working together to improve their competitiveness by sharing resources, skills, risks and costs", (Crispim and Sousa, 2005) and thus must be understood as a "consortium", that is to say that two or more different entities (natural or corporate) "get obliged to undertake certain activities or assuring certain contributions in order to make it possible to achieve certain material or legal acts" (Abreu, 2004), it must be foreseen also the possibility of software agents participating in more stable (not necessarily temporary) organizations. Actually, we must anticipate the possibility of software agents playing a determinant role in corporate bodies, in Virtual Enterprises, in Dynamic Virtual Organizations ("temporary alliances of organisations that come together to share skills or core competencies and resources in order to better respond to business opportunities"), and in Virtual Organisations Breeding Environments ("an association or pool of organisations and their related supporting institutions that have both the potential and the interest to cooperate with each other, through the establishment of a "base" long-term cooperation agreement"), (Camarinha Matos et al, 2005).

\section{CONCLUSIONS}

Of course further possibilities may be exploited. For instance, to foresee a new legal approach of the contract itself, considering not the agreement of wills but the result of the acts of machines or devices predisposed by human or corporate bodies. Or even to consider informatics systems as instruments capable of a sort of limited personhood, as it happens with some legal "realities" not personified but, for instance, capable of some kind of "procedural legitimacy": capable of being in Court, demanding and being sued, such as it happens with branches, agencies or other commercial establishments or even condominium.

It is obvious that the existing legal norms are not fit for such an endeavouring challenge as the appearance of intelligent electronic agents in electronic relations . The debate about Intelligent Inter-systemic contracting is still beginning. New developments are arising in the field of Artificial Intelligence such as the "embodying" of electronic "conversational agents" (Ball and Breese, 2003). Virtual persons will 
get more and more sophisticated, but also more identifiable. An dits participation in commercial companies and Virtual Organisations will be unavoidable. An ultimate choice must be made between the fiction of considering agents acts as deriving from human's will and the endeavour of finding new ways of considering the electronic devices own will and responsibility. And maybe in the virtual world - as it happened in the real world about corporate bodies - fictions will definitely be replaced by a more realistic approach considering that the challenging technical possibilities of software agents as new entities definitely require a particular legal approach in order to enhance the use of electronic commerce in a global world.

\section{Acknowledgments}

The work described in this paper is included in Intelligent Agents and Legal Relations project (POCTI/JUR/57221/2004), which is a research project supported by FCT (Science \& Technology Foundation - Portugal).

\section{REFERENCES}

1. Abreu JC. Curso de Dircito Comercial, Almedina, 2004 (in Portuguese).

2. Allen T, Widdison R. Can Computer Make Contracts?, Harvard Journal of Law and Technology, Volume 9, Number 1, Winter, 1996.

3. Almcida C. Contratos, Almedina, Coimbra, 2000 (in Portuguesc).

4. Andrade F, Neves J. Intelligent Electronic Inter-systemic Contracting - Issues on Consent and Contract Formation, ICEIS - Sixth International Conference on Enter-prise Information System Proccedings, vol. 4, pp 403-410, 2004.

5. Andrade F., Novais P., Machado J., Neves J. Contracting Agents: legal personality and representtation, Artificial Intelligence and Law, Springer, 2007 (to appear).

6. Andrade F., Novais P., Neves J. Issues on Intelligent Electronic Agents and Legal Relations, Procecdings of the LEA 2004 - Workshop on the Law of Electronic Agents, Roma, Italia, Cevenini C. (ed), Gedit edizioni, ISBN 88-88120-54-8, pp 81-94, 2004.

7. Andrade, MD. Tcoria Gcral da Rclação Jurídica, vol. I Coimbra Editora, 1974 (in Portuguesc).

8. Ball G, Breese J. Emotion and Personality in a Conversational Agent, Embodied Conversational Agents, edited by Justine Cassel, Joseph Sullivan, Scott Prevost and Elizabeth Churchill, The MIT Press Cambridge - Massachussets, London - England, 2000.

9. Barbagalo E. Contratos Eletrônicos - Editora Saraiva, São Paulo, 2001 (in Portuguesc).

10. Barficld, Woodrow "Issues of law for software agents within virtual environments", Pres-ence, Vol. 14, Issue 6-December 2005, The MIT Press.

11. Camarinha-Matos L, Afsarmanesh H, Ollus M. ECOLEAD: A holistic approach to creation and management of dynamic and virtual organizations, Collaborative Networks and Their Brecding Environments, Camarinha-Matos L. Afsarmanesh H., Ortiz A., (Eds), Springer-Verlag, ISBN 0-38728259-9, pp 501-512, 2005.

12. Crispim J, Sousa JP. A multi-Criteria support system for the formation of collaborative networks of enterprises, Collaborative Networks and Their Brecding Environments, Camarinha-Matos L. Afsarmanesh H., Ortiz A., (Eds), Springer-Verlag, ISBN 0-387-28259-9, pp 501-512, 2005.

13. Elias L, Gerard J. Formation of the contract by Electronic Data Interchange, pages 2-3

14. Elias L, Gerard J. Formation of the contract by Electronic Data Intcrchange", Commission of the Europcan Communitics, 1991.

15. Gentili A. L'inefficacia del contratto telematico, in "Rivista di Diritto Civile", Anno XLVI -, Parte I, Padova-Cedam, 2000.

16. Haentjens, Oliver van : "Shopping agents and their legal implications regarding Austrian Law", in http://www.cirfid.unibo.it/ lea-02/pp/Vanhaentjens.pdf, visited 2003/9/8, 2002.

17. Kcmradj, А.С. (Ксмрадж, А. С. ) : “Юридичсски сила сдслок, заключснных чсрсз ссть Интсрнст”, in "Правовыс аспскты использования Интернст-технологий”, Москва, Книжный Мир, 2002. 
18. Lerouge JF. The use of electronic agents questioned under contractual law. Suggested solutions on a European and American level, The John Marshall Journal of Computer and Information Law 18(2): 403-433, 2000.

19. Novais $\mathrm{P}$. Teoria dos Processos de Pré-Negociação em Ambientes de Comércio Electrónico, $\mathrm{PhD}$ Thesis, Departamento de Informática, Universidade do Minho, 2003 (in Portuguese).

20. Pacheco O, CarmoJ. A Role Based Model for the Normative Specification of Organized Collective Agency and Agents Interaction, Autonomous Agents and Multi-Agent Systems 6(2): 145-184, 2003.

21. Pacheco O. Especificação Normativa de Agentes Institucionais e da Interacção entre Agentes, Ph.D. Thesis, University of Minho, 2002 (in Portuguese).

22. Sartor G. Agents in Cyberlaw, Proceedings of the Workshop on the Law of Elec-tronic Agents (LEA 2002) and "Gli agenti software: nuovi sogetti del ciberdiritto?" in http://www.cirfid.unibo.it/sartor/ sartorpapers/gsartor2002_agenti_software.pdf, visited 2003/9/8

23. Thoumyre L. L'échange des consentements dans le commerce électronique, in Lex Electronica, vol. $5, \mathrm{n}^{\circ} 1,1999$.

24. Weitzenboeck E. Electronic Agents and the formation of contracts. International Journal of Law and Information Technology 9(3): 204-234, 2001.

25. Wettig S, Zehendner E. A legal analysis of human and electronic agents, Artificial Intelligence and Law archive Volume 12, Issue 1, pp 111-135, 2004.

26. Wettig S, Zehendner E. The Electronic Agent: A Legal Personality under German Law?. A.Oskamp \& E. Weitzenböck (eds.), Proceedings of the Law and Electronic Agents workshop (LEA'03), 2003. 